\title{
SUJEITO EM TRÂNSITO: FILIAÇÃO E RUPTURA AO MODERNISMO EM ARMANDO FREITAS FILHO
}

\section{SUBJECT IN TRANSITION: AFFILIATION AND RUPTURE WITH MODERNISM IN ARMANDO FREITAS FILHO'S POETRY}

Paulo ANDRADE ${ }^{1}$

\begin{abstract}
RESUMO: A poesia contemporânea revela identificação com os modernistas. Se esta afinidade se revela, muitas vezes, como "retradicionalização" (SIMON, 2011), em que os poetas fazem uso de formas, técnicas e procedimentos de modo conciliatório, evidenciando uma leitura mais de homenagem do que de crítica, em outros casos, porém, o diálogo se reveza entre convergências e conflitos com as poéticas de mestres como João Cabral, Carlos Drummond, Manuel Bandeira, entre outros. Armando Freitas Filho insere-se nesta segunda tendência da poesia brasileira, formada por poetas que buscam se libertar da tradição para trilhar um caminho singular. João Cabral é um dos principais poetas com os quais Armando Freitas Filho estabelece uma relação de permanente tensão. Se a relação entre Armando e Cabral se dá por meio da desleitura, do desvio, marcando sua filiação, pela diferença, os poemas dedicados a Drummond, publicados em Numeral/Nominal (2003), reveza entre
\end{abstract}

\footnotetext{
${ }^{1}$ Departamento de Literatura e Programa de Pós-Graduação em Estudos Literários, Faculdade de Ciências e Letras - Universidade Estadual Paulista - UNESP - CEP 14800-901 - Araraquara - SP - Brasil - pauloandrade@fclar.unesp.br
} 
um desejo de rivalizar com ele e com a impossibilidade de alcançá-lo.

PALAVRAS-CHAVE: tradição; intertextualidade; metalinguagem; Armando Freitas Filho; Carlos Drummond de Andrade

ABSTRACT: Contemporary poetry often presents identification with the Modernists and this affinity in many cases can reveal a "retraditionalization" (SIMON, 2011) in which the poets use forms, techniques and procedures in a conciliatory mode, through which their texts become rather tribute readings than critical works. However, in other cases, the dialogue interchanges between convergences and conflicts with the poetic works of masters such as João Cabral, Carlos Drummond de Andrade, Manuel Bandeira, among others. In this sense, Armando Freitas Filho integrates the second trend of Brazilian poetry, formed by poets who seek freedom from tradition so that they can trail a peculiar path. João Cabral is one of the major poets with whom Armando Freitas Filho establishes a relation of permanent tension. If the connection between Armando and Cabral is given by means of un-reading and deviation - determining their affiliation by difference -, on the other hand, the poems dedicated to Drummond published in Numeral/Nominal (2003) simultaneously displays an urge to compete with the poet and the impossibility of reaching him in terms of creative writing.

KEYWORDS: Tradition; intertextuality; metalanguage; Armando Freitas Filho; Carlos Drummond de Andrade.

"Você precisa se deixar inocular pelos poetas que te falam boca a boca. Só sendo possuído por eles vai poder fabricar anticorpos para, pelo menos, encará-los, sem deixar baixar os olhos, mesmo daqui do rés-dochão, como é o meu caso. Se não for assim você ficará paralisado, sem reação. E por mais pífia que seja essa reação, você tem que tentá-la, não uma vez, mas sempre, até o seu último dia" (FREITAS FILHO, 2000, p. 7 
"Se pudesse escolher, preferiria uma estrada mais calma e não esta - pedregosa - que Carlos Drummond abriu para todo sempre, para todos nós" (Id.ibid. p. 11)

Na contramão de algumas tendências na produção poética brasileira a partir dos anos 90, como a escrita minimalista e antidiscursiva, a ultraespecialização da linguagem com suas imagens raras e sublimes e o diálogo com o cânone modernista, a poesia de Armando Freitas Filho vem perfazendo um percurso cada vez mais singular, sem deixar, no entanto, de manter uma relação de permanente tensão com os seus mestres fundamentais. Um dos aspectos marcantes na obra de Armando Freitas Filho é a representação do ato de escrita. Para Rosa Maria Martelo (2010), a tematização do ato de escrita não é ingênua, nem destituída de sentido, mas, ao contrário, indicia "uma poética e também uma ética da escrita" (MARTELO, p.323), marcando, por meio do gesto metalingüístico, uma reflexão crítica do ato da sua própria escrita. 0 como se escreve é questão central na poesia de Armando. Neste artigo, iremos mostrar duas funções dessas encenações de escrita: a) marcar posição contra João Cabral, na obra Fio Terra (2000); b) assumir uma postura cambiante entre o desejo de rivalizar com Carlos Drummond e a consciência da impossibilidade de alcançálo, na sequência de poemas, em homenagem ao poeta mineiro, em Numeral/Nominal (2003).

0 gesto metalinguístico que, diga-se, não é um fenômeno contemporâneo, exerce papel fundamental na reflexão sobre a sua poética, revelendo procedimentos e formas. Como ilumina Martelo (2010, p.323), "faz parte da dimensão meta-reflexiva da poesia de tradição moderna a apropriação das cenas de escrita como um dos tópicos através dos quais a poesia se dobra sobre si mesma e a si mesma se mostra, pensa e analisa. No gesto de debruçar-se sobre si mesma, a poética de Freitas Filho deixa-se ver e assume sua filiação, marcando uma considerável diferença, em relação aos mestres modernistas, especialmente Cabral e Drummond. 
Em entrevista, Armando comenta a gênese de Fio terra. 0 livro surgiu quando o poeta ganhou um caderno de capa dura e passou a escrever diariamente durante três meses uma espécie de diário poético. Em certo momento decidiu então reescrevê-lo, dando-lhe a conformação atual, com 450 versos: "Fio Terra foi se articulando... da mão para a boca. Contrariando toda a minha 'psicologia da composição' (...) A poesia, quando não é homérica, quando é apenas lírica, te visita brevemente, sem avisar, e vai embora, sem se despedir". (NAVAS, 2000, p. 7-8).

A encenação, no sentido teatral, sobre a escrita poética, começa no próprio título, “3 V 98”, um suposto registro da data de um diário confessional, em que o sujeito reflete sobre a criação poética. Neste jogo, importam o onde escrever - o cenário criado para sustentar no tempo e espaço a captação do instante em que se inicia a escrita - e o como escrever, que se refere à reflexão sobre o ato de escrita:

\author{
Começa o dia e o caderno \\ ainda de dentro, por entre \\ as venezianas que listram \\ de sol e sombra, a folha \\ agora pautada, e sob a mão \\ Mas o que consegue ser escrito \\ na linha que a luz abre \\ não é tudo nem bastante \\ 0 que ficou atrás, no escuro \\ do rascunho, cego e rasurado \\ não pára, de irradiar - segrega \\ em código na entrelinha, o que só \\ passa através de frestas: \\ sussurro, perigo, perfume. \\ Embora adiado, insiste \\ em inscrever-se, intenso. \\ Senão com as palavras \\ com as sensações dos sentidos. \\ (FREITAS FILHO, 2000, p. 567)
}

As categorias positivas que transbordam no ambiente solar não se coadunam com a interioridade angustiante do eu lírico. A luz 
exterior que invade o espaço da intimidade não atinge o sujeito; não lhe possibilita clareza de pensamento, nem lhe possibilita projetar para a folha de papel, com clareza e exatidão, o que pretende dizer. Ao contrário, depara-se com situação de limite, de impossibilidade de transformar em linguagem corpórea o que está guardado no "caderno de dentro". Como dizer aquilo que quer dizer? Como dar materialidade à linguagem, de modo lúcido, nas pautas do "caderno de fora"?

Apesar do poema-diário marcar a passagem do tempo, nos títulos e nas datas à margem do livro, ao longo dos 450 versos, não há, no entanto, marcação da temporalidade. 0 tempo não introduz modificações. 0 sentido chega aos poucos, de modo nebuloso, desmedido de regras, pronto a revelar o que o "caderno de dentro" pretende exprimir.

Nessa tematização da escrita, o que está em jogo é menos a configuração que a afirmação de uma poética que, no ato da sua realização, já antecipa o seu fracasso. Por isso, é refratária à linguagem controlada e calculada, afinal "o que consegue ser escrito" "não é tudo nem o bastante". A escrita de Armando se mostra como um retorno do recalcado ou como uma escrita em palimpsesto, cujas marcas do rascunho, daquilo que foi apagado, ainda se revela. Por mais que se tente controlar o discurso, alguns elementos ("sussurro, perigo, perfume") insistem em aparecer. 0 que foi recalcado quer "inscrever-se", de modo deformado, "senão for com palavras" ao menos com as "sensações do sentidos"

O que está subjacente nesta poética é a negação do controle da sintaxe de João Cabral, mais precisamente o modelo de "Psicologia da Composição", poema metalinguístico que integra a trilogia publicada em 1947, Psicologia da composição, Fábula de Anfion e Antiode, e que reflete sobre o exercício de criação poética:

Esta folha branca

me proscreve o sonho, 
me incita ao verso

nítido e preciso.

Eu me refugio

nesta praia pura

onde nada existe

em que a noite pouse.

Como não há noite

cessa toda fonte;

como não há fonte

cessa toda fuga;

como não há fuga

nada lembra o fluir

de meu tempo, ao vento

que nele sopra o tempo.

(MELO NETO, 1994, p. 93-94)

A voz que anuncia o primeiro verso é assertiva e confiante, pois tem a certeza do êxito em sua realização: "Saio do meu poema/ como quem lava as mãos.”. 0 sujeito celebra a vitória da composição sobre o branco da folha, do intelecto sobre o sonho. Vence a habilidade técnica que atinge a forma pretendida, não porque foi "encontrada" ou obtida como um milagre ("em lance santo ou raro"), mas atingida pelo labor e atenção cerrada.

VI

Não a forma encontrada como uma concha, perdida nos frouxos areais como cabelos;

não a forma obtida em lance santo ou raro, tiro nas lebres de vidro do invisível;

mas a forma atingida 
como a ponta do novelo

que a atenção, lenta,

desenrola,

aranha; como o mais extremo

desse fio frágil, que se rompe

ao peso, sempre, das mãos

enormes.

(MELO NETO, 1994, p. 95-96)

A representação do ato de escrita cabralina aponta para uma poética do controle sintático, por meio de versos "nítidos e precisos", e para uma habilidade técnica de tecer o verso, os fios frágeis, tal uma aranha, com extrema meticulosidade. No universo cabralino, tudo o que precisa dizer está dito. Nenhum recalque, "sussurro" que ficou no rascunho segrega ou quer inscrever-se. Esta poética vai ao encontro do pensamento crítico de Wimssat e M. Beardsley (1954), segundo o qual o êxito de um poema está em sua eficácia, em sua capacidade de funcionamento, como se exige de uma máquina qualquer.

A poesia é uma operação do estilo pela qual um complexo de significado é apreendido de um só golpe. A poesia triunfa porque tudo ou quase tudo que nela se diz ou se encontra implícito é relevante; o que não importa foi excluído, como os caroços de um pudim ou os enguiços de uma máquina (WINSATT; BEADERSLEY, 1983, p. 87).

$\mathrm{Na}$ representação da escrita de "Psicologia da composição", interessa ao enunciador que o espetáculo se mostre pronto, em sua autonomia no palco da linguagem, e não em seu processo de composição e seus percalços. Na representação do ato de escrita de Armando, ao contrário, o eu lírico permite que se veja todo o processo, toda a maquinaria utilizada na composição, sobretudo o que foi rasurado, apagado, volta através das frestas.

Faz parte da poética de Freitas Filho este misto de reverência 
e confronto, de louvor e crítica à tradição modernista e, por isso mesmo, sua escrita possui papel de relevo na cartografia da poesia brasileira, como bem assinala Célia Pedrosa $(2003$, p.02) a respeito da reunião de obra, intitulada Máquina de escrever (2003):

o sólido chão da tradição moderna se transforma em trampolim para um salto no escuro, como diz Drummond. Armando redesenha o legado de nossa melhor estética moderna e sinaliza os vínculos com seu próprio tempo, fazendo da obra reunida, uma alegoria de sua vontade de não ser um sobrevivente de si mesmo, mas um contemporâneo, lembrando as palavras de Murilo Mendes a respeito de sua própria obra reunida. (PEDROSA, 2013, p.02)

A consciência de débito em relação à herança modernista não significa repetir o legado, ao contrário, ela é impulsionadora de permanente diálogo crítico, ora como confronto, ora como desejo de superação. Sem abdicar da evidente filiação de sua poesia à tradição cabralina, Freitas Filho não escamoteia as especificidades históricas em que está inserido, mas, como herdeiro, recusa o papel de mero seguidor, inscrevendo-se num espaço tenso a sua condição de poeta no/do tempo presente.

Essa relação problemática faz dele um poeta a contrapelo dos seus pares contemporâneos ou mesmo distante da ideia de "retradicionalização frívola", exposta por Simon (2011). A fim de avaliar o impacto da matriz modernista em sua obra, exporemos adiante o modo como o poeta reage e dramatiza, no espaço da linguagem, sua atitude de permanente desafio frente à poética drummondiana e cabralina.

João Cabral de Melo é um destes poetas pelos quais Armando Freitas Filho se deixou inocular, conforme assinalado na epígrafe. No entanto, a poética de Cabral projeta-se na obra de Freitas Filho ora de modo pacífico, ora conflituoso. Dialogando com seu antecessor, o poeta também busca libertar-se do seu peso: "0 que vejo, enfim, quando sou retrospectivo, para ficar só no âmbito do 
literário, que é um lugar mais ameno no meio da minha vida, é que escrevi, escrevo, o que posso, não o que devo, e o que posso está muito aquém do que devo" (apud ROSA; OLIVEIRA, 2000, p.06).

A consciência de escrever o que é possível e não o que deve, ganha amplitude na poesia brasileira para muitos poetas pós-50, como Sebastião Uchoa Leite e José Paulo Paes, que enfrentam a crise da palavra poética em língua portuguesa do Brasil. Ítalo Moriconi (1992, p. 27) observa que "ofuscado pelo apogeu da estética modernista, o poeta, que já não pode renová-la, só pode repetila" (...).. Repetir, entretanto, é um gesto distante das estratégias de Armando, que prefere marcar posição pelo contraste. É este instigante contraponto que permite a um "poeta forte" (Bloom, 1991), como Armando, inscrever-se na tradição da poesia brasileira, deslendo com rigor e vigor os poetas fortes do modernismo.

Quanto ao cenário poético de ontem e o de hoje, posso constatar, agora, quando, infelizmente, tenho mais espelhos retrovisores disponíveis e menos pára-brisas, que o que conta, de verdade não é o pró, é o contra. Ele é que tempera e, mesmo sabendo que vou ser derrotado (pois esses olhos da mocidade que vem chegando verão a minha morte física), é esse oponente, às vezes todo sorriso, que, no fundo, me faz viver, me mantém em alerta e não me deixa sentar e engordar, antes da hora, de costas para a porta aberta. (apud. ROSA; OLIVEIRA, 2000, p. 6).

A atitude de estar contra, exercitada por meio da intensa reavaliação que faz da obra de João Cabral, desafiando um dos modelos que mais admira, é o que impulsiona Freitas Filho a inserir-se na tradição. A autoconsciência das diferenças contextuais - a que foi experenciada por João Cabral e a que foi vivenciada por ele, no cenário contemporâneo - incita-o a adotar uma postura ambivalente. Ao renunciar à engenharia e à arquitetura cabralina, estabelece forte aproximação com esta mesma poética. Paradoxalmente, verifica-se um impulso de negação em relação àquilo mesmo que admira, inclusive no plano biográfico, uma vez 
que João Cabral foi um poeta com quem Armando manteve fortes laços de amizade.

Neste diálogo crítico e combativo que Armando desenvolve "com e contra Cabral", "pode-se reconhecer o quanto a sua obra se distancia de qualquer formalismo sem deixar de absorver todas as consequências da autonomia da linguagem poética, liberta tanto das amarras do objetivismo quanto do biografismo" (GUERREIRO, 2002, p. 15).

0 diálogo com a tradição modernista vem acompanhado do jogo metalinguístico recorrente na poesia do autor de Fio Terra. Compreender este diálogo é significativo pelo fato de representar uma reflexão sobre esta poética que quer estar contra. 0 poema "Para João, com amor e sordidez", publicado em Duplo Cego (2003, p.541) e que traz a epígrafe "Ninguém aqui está interessado em ser simpático", extraída de J. D. Salinger, é bom exemplo deste amor por contraste:

\author{
Exercício de estilo, se existe \\ Não visa, como o de tiro \\ Um alvo único, fixo e físico \\ Mas a muitos \\ Mais de imaginação do que de imagem. \\ Não usa bala burocrática, numerada \\ De calibre certo, didático. \\ E sim um punhado de chumbo \\ De pedras \\ Que pega um pouco em tudo \\ Assinando o nome com garranchos \\ Sem carimbo \\ Ou caligrafia pré-fabricada \\ Picotando o papel jornal com furos de franco-atirador. \\ (FREITAS FILHO, 2003, p.541)
}

Um recado com endereçamento nominal, o poema rasura a um só tempo, o sistema unívoco ("que visa um alvo único, fixo e físico"), a gramática de contenção, de precisão, o rigor construtivo alcançado pelo controle da sintaxe e, sobretudo, pelo controle do discurso do 
mestre pernambucano. 0 que se lê é uma acusação inclemente da poética cabralina, para sinalizar o que não se deve repetir: a poética didática, monocórdica, bala de "calibre certo" ou burocrática. 0 gesto é de afrontamento, mas, para Armando, só é possível amá-lo por meio desta sordidez. Como afirma em entrevista Adolfo Montejos Navas (2000): “João Cabral, poeta fundamental - mas péssima influência quando lido de modo servil -, tem de ser enfrentado pelos que vêm depois, até para que possamos, por contraste, amálo melhor. [...] Senti muito a sua morte." (NAVAS, 2000, p. 9). Tratase de uma demarcação de terreno onde a psicologia da composição é exposta como contramodelo. Utilizando o método cabralino de comparar pela oposição, Armando não pretende obter o total controle da linguagem.

O poema estabelece uma série de distinções entre o seu "exercício de estilo" e o de Cabral, tomando como ponto de comparação a metáfora do "tiro", ou melhor, dos "modos de atirar": um que privilegia a imagem, densa, concentrada do objeto e a outra, que usa a imaginação, aberta, plural. Partindo do verbo intransitivo não "visa", no sentido de "dirigir o olhar para ou apontar arma de fogo contra" o poema vai se expandido o seu discurso bélico (tiro, alvo, bala, calibre, chumbo, pedras) até finalizar com a presença da imagem do atirador altamente especializado, o franco-atirador.

0 alvo a ser atingido aqui é a estratégia composicional do poema Uma faca só lâmina (1955), um dos poemas metalingüísticos mais sistematizados de Cabral e que gira em torno de eixos semânticos permanentes, que beira à obsessão, pelo grau de concentração e interconexões das imagens que perpassam suas oito estrofes. Cabral explora um limitado campo semântico, com imagens que remetem à ideia de acuidade, contundência, acentuando os sentidos que vão de "bala" a "faca", ao "relógio", retornando da última (faca) à primeira (bala). Se, no poema de Cabral, a bala calculada é de "calibre certo", Freitas Filho aconselha lançar as pedras aos punhados, que, ao serem lançados, atinjam muitos alvos inesperados.

A assinatura é um entre tantos indícios de como a escrita de 
Armando evidencia as marcas das contingências, do tempo vivido, incerto, "assinando o nome com garranchos", inscrevendo nesta assinatura as marcas do corpo. Como afirma Sérgio Alcides (1997, p. 100), a poesia de Armando "é da experiência, do experimento, mas não em laboratório tecnocrático, e sim na vida.

\section{Sobre Drummond: a presença que falta}

Se a relação entre Armando e Cabral se dá por meio da desleitura, pela diferença, a longa sequência de poemas em homenagem a Drummond, publicada em Numeral/Nominal (2003), evidencia outra problemática de filiação. Há um nítido desejo de rivalizar com o poeta mineiro, mas, ao mesmo tempo, emerge a consciência da impossibilidade de alcançá-lo. 0 fracasso é anunciado antes de realizar o desafio.

Na segunda parte, "Nominal" figura uma longa sequência de poemas dedicados ao poeta mineiro, uma tentativa de decifrar os mecanismos da máquina de Drummond. Começamos pela leitura de "Pensando em Drummond e Clarice":

A máquina de um, a outra se sentindo uma, e a minha: mecânica, não oferecida tampouco entranhada, enferruja sem metafísica ou metáfora perdendo força a cada dia não dizendo o que durante tanto tempo prometeu - ilusão não era pois o mundo palpita para todos.

0 que faltou foi velocidade na datilografia, acurácia, para captar o que sub-reptício se afastava e mesmo se gritante, os dedos gagos não conseguiam, nas teclas, articular as palavras, o que se exprimia, próximo 
mas sempre além de todo o mecanismo que embora igual aos outros, desistia.

(FREITAS FILHO, 2003, p. 47)

Descrição angustiada do seu deparar-se com os próprios limites diante de uma máquina que não se oferta, como a máquina do mundo, que não se revela. Angústia por não materializar-se no seio da linguagem o que se pretende dizer. Seus dedos gagos não permitem a velocidade, a acurácia para "Captar o que subreptício se afastava”. Há, em Armando, um vasto campo semântico que aproxima Drummond de uma espécie de miragem. 0 poeta de Itabira representa a voz forte da qual Armando gostaria de se apropriar, mas cuja presença é ausente e muito distante. É esta presença tão ausente que é descrita no poema "CDA no coração":

Drummond é Deus. Pai inalcançável.

Não reconhece os filhos. A mão ossuda

E dura, de unhas rachadas, não abençoa:

Escreve, sem querer, contudo, a vida

De cada um, misturada com a sua.

Sangue da mesma família, carne

Igual - de milagre e tigre - continua

A se emendar, ferida após ferida.

(...)

(id. ibid. p. 59)

Espécie de código genético, o poeta de Itabira é uma matriz que deu origem a toda uma herança de uma poesia que alia distanciamento crítico e subjetividade, poesia e experiência, vida e linguagem, com as quais o sujeito poético se identifica. Mais do que reproduzir, o interesse aqui é decifrar as estruturas dos genes para apreender o cerne da máquina drummondiana. 0 discurso de veneração deixa vazar certa decepção, resignação instaurada pelo distanciamento desta presença que falta: "Sangue da mesma família" "carne/igual" este pai não permite ser alcançável por nenhum filho. 
E, diante da impossibilidade de decifrar este deus inalcançável, prenhe de humanidade, mas que não se permite moldar-se, modelarse, pois está sempre além, o sujeito lírico sente-se frustrado, como atestam os versos de "Palavra chave", poema que dialoga com "À procura da poesia":

(...)

O encaixe desta chave não se corta a priori: seu ajuste se molda a partir da febre que o instante forja - fugaz.

Não se faz cópia, do que não se funde Nem memoriza o fecho, a nuvem cinzenta Do seu segredo volátil: então se perde completamente, amnésica isolada, imperfeita, inútil no fundo da gaveta, do pensamento Até que a imaginação refaça Em outra liga de duração semelhante Sua imagem de uso e magia (id. ibid. p. 62-63)

Um desejo quase religioso de sacralizar tanto a obra quanto o poeta-pai e a ele religá-lo, como se quisesse ver a face do inapreensível, repete-se no poema "CDA na cabeça":

Sua pedra é do castelo

Do esforço da montanha

Em apurá-lo, com céu e neve. E como um traço de horizonte Ao fundo, para iludir melhor Quem o quer alcançar - logo ali Logo além - sempre recuando À mão agrimensora que refaz. O cálculo, toda vez, mas acaba Por contar incerto, e se interrompe.

Sua pedra é do castelo

Não soletra nem se metaforiza. 
Não se deixa paginar - bruta

Não se lapida nunca, não

Se faz rara, nenhuma máquina

A consegue aparar, pois se parte

E se funde, no trabalho, a ela:

Peça engastada de ferro, aresta

Calcária, rocha, barra e fere

0 passo do caminho, as mãos presas.

(id. ibid. p 61)

Entre a gratidão e a admiração intelectual, metáforas e imagens circulam em torno do poeta de Itabira, ressaltando sua presença intangível. Drummond é a linha do horizonte, que ilude quem quer alcançá-lo ("está logo ali, logo além").

Há algo de Sísifo neste sujeito que busca apreender os segredos da máquina Drummond. A estrada pedregosa, aberta pelo poeta mineiro, incita-o a percorrê-la. Mas o poeta desiste para perfazer o seu próprio percurso: "À mão agrimensora que refaz./O cálculo, toda vez, mas acaba/Por contar incerto, e se interrompe". 0 gesto de "contar incerto", instaura no ato da sua escrita a errância e o imponderável, interrompendo o percurso da procura.

É a inserção da experiência, a transformação da vida em linguagem, "sem ser calculado e sem contagem", o ponto de intersecção da poética de Armando com a de Drummond. Corpo e subjetividade impregnam todo o tecido textual, sem que isso signifique centralização narcísica. Ao contrário, trata-se de um sujeito em permanente trânsito, "à deriva", "ficcionalizado", "ferido" e compulsivo.

A "pedra bruta, que não se lapida e não se faz rara", assim como seu sistema plural que abarca o vasto mundo são os elementos admirados em Drummond e, por confronto, rejeitados em João Cabral. No entanto, a confrontação cabralina não exclui a "inevitável marca de Cabral na economia de sua escritura". (LOSSO, 2002, p. 14). Uma escrita que assume os riscos e as incertezas da linguagem, mas sem abandonar o rigor. 0 poeta impulsivo, desenfreado e hostil, 
é o mesmo que baliza e controla o verso, fazendo conviver exatidão e abismo, construtivismo e impureza.

A leitura de Armando nos fornece subsídios para entender como as gerações contemporâneas vivenciam a modernidade não mais como uma "tradição da ruptura", mas como dilema em relação tanto com o tempo presente quanto com os poetas modernistas.

\section{Referências bibliográficas}

BLOOM, H. A angústia da influência; uma teoria da poesia. Rio de Janeiro: Imago, 1991.

ELIOT, T. S.Tradição e talento individual. In:_Ensaios. São Paulo: Art Editora, 1989.

FREITAS FILHO, A. Máquina de escrever: poesia reunida e revista. Rio de Janeiro: Nova Fronteira, 2003.

. Três Mosqueteiros. In: MASSI. A. (Org) Artes e Ofícios

da poesia. São Paulo e Porto Alegre: Secretaria Municipal de Cultura e Ofícios. 1991.

GUERREIRO. E.G.B. Travessia cega de um desejo incurável: a experiência sublime na obra de Armando Freitas Filho. Dissertação de Mestrado. Rio de Janeiro: UFRJ, 2002.

MARTELO, R. M. A forma informe: leituras de poesia. Lisboa: Assírio Alvim, 2010.

MASSI. A. (Org) Artes e Ofícios da poesia. São Paulo e Porto Alegre: Secretaria Municipal de Cultura e Ofícios. 1991. 
MELO NETO, J. C. de. Obra completa. Rio de Janeiro: Nova Aguilar, 1994.

NAVAS, A. M. Correspondencia celeste; nueva poesía brasileña (1960-2000). Madri: Árcora Ediciones, 2001.

PEDROSA, C. O poeta definitivo. Jornal do Brasil, Rio de Janeiro, 29 nov. 2003. Idéias, p. 2-3.

ROSA. M. A; OLIVEIRA. A. Coisa incerta. Suplemento Literário Minas Gerais. Belo Horizonte, 10 de novembro de 2000.

SECCHIN. A. C. João Cabral: a poesia do menos. São Paulo: Duas cidades; Brasília: INL, Fundação Nacional Pró-Memória, 1985.

SIMON, I. M.; DANTAS, V. Negativo e ornamental. Um poema de Carlito Azevedo em seus problemas. Novos estudos, CEBRAP, n. 91, São Paulo, nov. 2011.

SIMON, I. M. Condenados à tradição. 0 que fizeram com a poesia brasileira. Revista Piauí, n 61, 2011. http:// revistapiaui.estadao.com.br/edicao-61/aceleracao-docrescimento/condenados-a-tradicao. acessado no dia 09 de janeiro de 2012.

WINSATT W.K.; BEADERSLEY, M.C. A falácia intencional. In: COSTA LIMA. L. (Org.). Teoria da literatura em suas fontes. Rio de Janeiro: Francisco Alves 1983. p. 86-103. 
